\title{
Association of MHC class III gene polymorphisms with ER-positive breast cancer in a Chinese Han population
}

\author{
Q. Pan ${ }^{1 *}$, Y. Ning ${ }^{1 *}$, L.Z. Chen ${ }^{2}$, S. Zhang ${ }^{1}$, Z.Z. Liu ${ }^{1}$, X.X. Yang ${ }^{3}$, \\ W. Wei ${ }^{3}$, H. Wei ${ }^{1}$, Q.G. Li ${ }^{2}$, H.N. Yue ${ }^{2}$ and J.X. Wang ${ }^{2}$ \\ ${ }^{1}$ Laboratory of Medical Genetics, \\ Huaian Maternal and Child Health Care Hospital, Huai'an, \\ Jiangsu Province, China \\ ${ }^{2}$ Department of Breast Surgery, \\ Huaian Maternal and Child Health Care Hospital, Huai'an, \\ Jiangsu Province, China \\ ${ }^{3}$ School of Biotechnology, Southern Medical University, Guangzhou, China \\ *These authors contributed equally to this study. \\ Corresponding authors: J.X. Wang / X.X. Yang \\ E-mail: wjinxing@yahoo.cn / yxxzb@sohu.com
}

Genet. Mol. Res. 11 (4): 4299-4306 (2012)

Received November 29, 2011

Accepted June 30, 2012

Published September 17, 2012

DOI http://dx.doi.org/10.4238/2012.September.17.1

\begin{abstract}
Polymorphisms of the major histocompatibility complex (MHC) have been linked to many diseases, especially autoimmune disorders. Previous studies have shown that genetic variants in MHC class III are associated with breast cancer. To determine if there is an association between MHC class III and breast cancer risk in the Chinese Han population, we carried out a hospital-based case-control study in Guangdong and Jiangsu Provinces, including 216 histologically confirmed breast cancer patients and 216 healthy controls. Nine SNP markers distributed
\end{abstract}


in the class III-coding region were detected using the Sequenom MassARRAY ${ }^{\circledR}$ iPLEX System. Deviation from Hardy-Weinberg equilibrium was observed for seven SNPs. There was no significant association between these seven SNP variants and breast cancer in these Chinese women (unconditional logistic regression analysis). However, chr6_31697494 at BAT2, one of the seven SNPs, was found to be significantly associated with both ER- and PR-positive breast cancer. In addition, both chr6 31911109 at C6orf48 and chr6_31975605 at ZBTB12, another two of the seven SNPs, show relevance with ER-positive breast cancer. In conclusion, this is the first evidence that genetic polymorphisms in the MHC class III region are significantly associated with ER-positive breast cancer in the Han Chinese population.

Key words: Breast cancer; MHC class III; Chinese Han population; Single nucleotide polymorphism

\section{INTRODUCTION}

Breast cancer is one of the most common fatal malignant diseases of women, where its incidence has been ranked number one (Jemal et al., 2011). Compared to Western countries, breast cancer incidence is currently lower in China, but the rate of breast cancer in China is expected to increase substantially, from 10-60 cases per 100,000 women in 2008 to more than 100 cases per 100,000 women aged 55-69 years by 2021 (Linos et al., 2008; Ziegler et al., 2008). Therefore, there is an urgent need to find key factors for breast cancer in Chinese women, and to take effective measures to control the incidence of breast cancer.

The major histocompatibility complex (MHC) is a group of genes with a high degree of polymorphism, and it is closely linked to a genomic region found in most vertebrates that is associated with reproduction and the immune system. The immune system is able to discriminate between normal and malignant tissues and to protect the host from tumor development by the recognition and subsequent elimination of aberrant cells (Dunn et al., 2002). Failure of immune surveillance could lead to the formation of a tumor. Therefore, MHC plays an important role in antitumor immune response and immune surveillance through recruiting cytotoxic $\mathrm{T}$ lymphocytes against tumor antigens (Bhutia et al., 2010).

A subset of the human MHC is human leukocyte antigen (HLA), which controls the antigen-presenting system. HLA located in the short arm of chromosome 6 , is a highly variable region, which mainly contains class I, class II and class III. Among these, class I molecules are found in all nucleated cells and present peptides to cytotoxic T cells. Class II molecules are found in certain immune cells and present tumor antigenic peptides on the cell surface to be recognized by T lymphocytes. Class III molecules are several secreted proteins with immune functions. It is clear that class III genes do not share the same function as class I and class II genes, but they are located between them in the short arm of human chromosome 6 . For this reason they are frequently described together. 
In recent years, a large number of data have been published on the role of MHC (also called HLA) class I and class II genes in recruiting of the cytotoxic T lymphocytes to mount a response against tumor antigens. However, there are few reports of HLA class III alleles in the Chinese female population with breast cancer. Therefore, it is necessary to investigate whether HLA class III variants are associated with breast cancer susceptibility or prognostics in the Chinese Han population. In this study, we investigated 9 single nucleotide polymorphisms (SNPs) in the class III coding region in the Chinese Han population using the MassARRAY ${ }^{\circledR}$ iPLEX SNP genotyping. Although there were no statistical risk variants for breast cancer in the case-control study, the further study of positive- or negative-estrogen receptors (ERs) revealed that C6orf48 chr6_31911109 and ZBTB12 chr6_31975605 variants were involved in good prognosis of breast cancer patients in the Chinese Han population.

\section{MATERIAL AND METHODS}

\section{Study population}

Following pathology-based diagnoses, 216 patients with breast cancers were enrolled at the Nanfang Hospital, Southern Medical University, Guangzhou, Guangdong Province, at Huai' an Maternal and Child Health Care Hospital, Huai'an, Jiangsu Province, P.R. China. The control group consisted of 216 subjects with no cancer of any type. The mean ages of the patients and the control subjects were 47.62 and 47.46 years, respectively. All subjects involved were Chinese Han women, and all subjects with clinical data provided informed consent before participating in the trial.

Additionally, the existence of estrogen and progesterone receptors in the tumor tissue was examined. The hormonal receptors of these tumors were distributed as follows: positiveERs (ER-positive) in 53 cases, negative-ERs (ER-negative) in 136 cases, positive-progesterone receptors (PR-positive) in 93 cases, and negative-PRs (PR-negative) in 96 cases. In 27 cases, it was impossible to study both ERs and PRs.

\section{Genotyping}

Peripheral blood samples $(5 \mathrm{~mL})$ were collected after informed consent, and they were delivered and stored in a frozen state. Genomic DNA was extracted from $200 \mu \mathrm{L}$ peripheral blood using a Genomic DNA Purification kit (Omega, China) according to manufacturer instructions and stored at $-70^{\circ} \mathrm{C}$ until use. All SNPs were genotyped using Sequenom MassARRAY matrix-assisted laser desorption ionization-time of flight mass spectrometry platform (Sequenom, USA). Primers were designed using a semiautomated method (Assay Design 3.1, Sequenom). The call rate for each assay was set at $>90 \%$.

\section{Statistical analysis}

Hardy-Weinberg equilibrium (HWE) was examined using Haploview 4.1. Co-dominant, dominant, and recessive genetic models of inheritance were chosen to evaluate synthetically the associations between each SNP and breast cancer. We further divided the cases 
into different groups according to the status of ERs or PRs. Association analysis based on unconditional logistic regression was carried out by calculating the odds ratio (OR) and $95 \%$ confidence interval $(95 \% \mathrm{CI})$ for each SNP in the codominant and dominant genetic model; the significance level was set at $\mathrm{P}<0.05$. The statistical tests were implemented in the web-based tool SNPstats (http://bioinfo.iconcologia.net/SNPstats).

\section{RESULTS}

Of the 9 SNPs analyzed in the case-control study, 7 SNPs (chr6_31911109, chr6_31783744, chr6_32286548, chr6_31697494, chr6_31763660, chr6_31975605, chr6_32248546) conformed to Hardy-Weinberg proportions in the controls $(\overline{\mathrm{P}}>0.1$; data not shown). The statistical analysis of only these 7 variants is outlined here, while statistical analysis data of the other variants are supplied as supplements. However, no statistically significant differences between the case and control groups were detected in the Han Chinese population (Table 1).

In both ER- and PR-positive/-negative groups (Tables 2 and 3), chr6_31697494 in BAT2 showed a significant association with breast cancer, with zero C $\overline{\mathrm{T}}$ genotyping in the ER- and PR-negative groups. In the ER-positive/-negative study (Table 2), chr6_31911109 in C6orf48 was linked to ER-positive breast cancer, with OR $=2.01$ $(95 \% \mathrm{CI}=1.02-3.96 ; \mathrm{P}=0.038)$. However, when evaluations were made for PR, there was a statistically insignificant correlation between C6orf 48 and PR positivity in breast cancer ( $\mathrm{P}=0.2$; Table 3). In addition, chr6 31975605 in ZBTB12 was found to confer a statistically significant correlation with $\overline{\mathrm{E} R}$-positive breast cancer, with $\mathrm{OR}=2.04$ $(95 \% \mathrm{CI}, 1.12-3.71 ; \mathrm{P}=0.019)$ for $\mathrm{GC}$ and $\mathrm{GG}$ in the genetic dominant model (Table 2). Also, chr6_31975605 showed a statistically insignificant association with PR-positive breast cancer $(\mathrm{P}=0.58$; Table 3$)$.

\begin{tabular}{|c|c|c|c|c|c|c|c|c|}
\hline Nearest gene & SNP_ID & ID & Model & Genotype & Case $(\mathrm{N})$ & Control (N) & OR $(95 \% \mathrm{CI})^{\mathrm{a}}$ & $\mathrm{P}^{\mathrm{b}}$ \\
\hline \multirow[t]{2}{*}{$\overline{B A T 2}$} & chr6_31697494 & snp3363 & - & $\mathrm{C} / \mathrm{C}$ & $210(98.1 \%)$ & $204(96.2 \%)$ & 1 & 0.23 \\
\hline & & & & $\mathrm{C} / \mathrm{T}$ & $4(1.9 \%)$ & $8(3.8 \%)$ & $2.06(0.61-6.94)$ & \\
\hline \multirow[t]{2}{*}{ BAT5 } & chr6_31763660 & snp3425 & Codominant & $\mathrm{C} / \mathrm{C}$ & $177(83.5 \%)$ & $172(82.3 \%)$ & 1 & 0.31 \\
\hline & & & & $\mathrm{T} / \mathrm{C}$ & $31(14.6 \%)$ & $36(17.2 \%)$ & $1.20(0.71-2.02)$ & \\
\hline \multirow[t]{2}{*}{$L Y 6 G 6 F$} & chr6_31783744 & rs2242653 & Codominant & $\mathrm{G} / \mathrm{G}$ & $167(79.2 \%)$ & $163(78 \%)$ & 1 & 0.13 \\
\hline & & & & $\mathrm{A} / \mathrm{G}$ & $43(20.4 \%)$ & 40 (19.1\%) & $0.95(0.59-1.54)$ & \\
\hline \multirow[t]{2}{*}{ C6orf48 } & chr6_31911109 & rs17201248 & Codominant & $\mathrm{C} / \mathrm{C}$ & $145(67.8 \%)$ & $155(73.8 \%)$ & 1 & 0.35 \\
\hline & & & & $\mathrm{C} / \mathrm{T}$ & $61(28.5 \%)$ & $50(23.8 \%)$ & $0.77(0.50-1.19)$ & \\
\hline \multirow[t]{3}{*}{ ZBTB12 } & chr6_31975605 & snp704 & Codominant & $\mathrm{C} / \mathrm{C}$ & $123(56.9 \%)$ & $137(64.6 \%)$ & 1 & 0.16 \\
\hline & & & & $\mathrm{G} / \mathrm{C}$ & $85(39.4 \%)$ & $65(30.7 \%)$ & $0.69(0.46-1.03)$ & \\
\hline & & & & $\mathrm{G} / \mathrm{G}$ & $8(3.7 \%)$ & $10(4.7 \%)$ & $1.12(0.43-2.93)$ & \\
\hline \multirow[t]{3}{*}{$A G P A T I$} & chr6_32248546 & snp725 & Codominant & $\mathrm{A} / \mathrm{A}$ & $155(72.8 \%)$ & $150(71.4 \%)$ & 1 & 0.7 \\
\hline & & & & $\mathrm{G} / \mathrm{A}$ & $53(24.9 \%)$ & $57(27.1 \%)$ & $1.11(0.72-1.72)$ & \\
\hline & & & & $\mathrm{G} / \mathrm{G}$ & $5(2.4 \%)$ & $3(1.4 \%)$ & $0.62(0.15-2.64)$ & \\
\hline \multirow[t]{2}{*}{ NOTCH4 } & chr6_32286548 & rs17604492 & Codominant & $\mathrm{C} / \mathrm{C}$ & $179(83.3 \%)$ & $184(86.4 \%)$ & 1 & 0.64 \\
\hline & & & & $\mathrm{T} / \mathrm{C}$ & $33(15.3 \%)$ & $26(12.2 \%)$ & $0.77(0.44-1.33)$ & \\
\hline
\end{tabular}

a The corresponding odds radio (OR) is counted by age and gender adjustment. $95 \% \mathrm{CI}=95 \%$ confidence interval. ${ }^{\mathrm{b}}$ The $\mathrm{P}$ value is counted by the web-based tool SNPstats. 
Table 2. Results of 7 single nucleotide polymorphisms (SNPs) in ER-positive/-negative groups.

\begin{tabular}{|c|c|c|c|c|c|c|c|c|}
\hline Nearest gene & SNP_ID & ID & Model & Genotype & Positive (N) & Negative $(\mathrm{N})$ & OR $(95 \% \mathrm{CI})^{\mathrm{a}}$ & $\mathrm{P}^{\mathrm{b}}$ \\
\hline \multirow[t]{2}{*}{$B A T 2$} & chr6_31697494 & snp3363 & - & $\mathrm{C} / \mathrm{C}$ & $73(96 \%)$ & $111(100 \%)$ & 1 & 0.019 \\
\hline & & & & $\mathrm{C} / \mathrm{T}$ & $3(4 \%)$ & $0(0 \%)$ & $0.00(0.00-\mathrm{NA})$ & \\
\hline \multirow[t]{3}{*}{ BAT5 } & chr6_31763660 & snp3425 & Codominant & $\mathrm{C} / \mathrm{C}$ & $67(87 \%)$ & $88(81.5 \%)$ & 1 & 0.6 \\
\hline & & & & $\mathrm{T} / \mathrm{C}$ & $9(11.7 \%)$ & $18(16.7 \%)$ & $1.52(0.64-3.60)$ & \\
\hline & & & & $\mathrm{T} / \mathrm{T}$ & $1(1.3 \%)$ & $2(1.8 \%)$ & $1.52(0.14-17.1)$ & \\
\hline \multirow[t]{3}{*}{$L Y 6 G 6 F$} & chr6_31783744 & rs2242653 & Codominant & $\mathrm{G} / \mathrm{G}$ & $59(76.6 \%)$ & $86(80.4 \%)$ & 1 & 0.44 \\
\hline & & & & $\mathrm{A} / \mathrm{G}$ & $18(23.4 \%)$ & $20(18.7 \%)$ & $0.76(0.37-1.56)$ & \\
\hline & & & & $\mathrm{A} / \mathrm{A}$ & $0(0 \%)$ & $1(0.9 \%)$ & NA $(0.00-N A)$ & \\
\hline \multirow[t]{5}{*}{ C6orf 48} & chr6_31911109 & rs 17201248 & Codominant & $\mathrm{C} / \mathrm{C}$ & $58(75.3 \%)$ & $70(63.6 \%)$ & 1 & 0.095 \\
\hline & & & & $\mathrm{C} / \mathrm{T}$ & $16(20.8 \%)$ & $38(34.5 \%)$ & $1.97(1.00-3.88)$ & \\
\hline & & & & $T / T$ & $3(3.9 \%)$ & $2(1.8 \%)$ & $0.55(0.09-3.42)$ & \\
\hline & & & Overdominant & $\mathrm{C} / \mathrm{C}-\mathrm{T} / \mathrm{T}$ & $61(79.2 \%)$ & $72(65.5 \%)$ & 1 & 0.038 \\
\hline & & & & $\mathrm{C} / \mathrm{T}$ & $16(20.8 \%)$ & $38(34.5 \%)$ & $2.01(1.02-3.96)$ & \\
\hline \multirow[t]{5}{*}{ ZBTB12 } & chr6_31975605 & snp704 & Codominant & $\mathrm{C} / \mathrm{C}$ & $52(66.7 \%)$ & $55(49.5 \%)$ & 1 & 0.04 \\
\hline & & & & $\mathrm{G} / \mathrm{C}$ & $23(29.5 \%)$ & $53(47.8 \%)$ & $2.18(1.17-4.05)$ & \\
\hline & & & & $\mathrm{G} / \mathrm{G}$ & $3(3.8 \%)$ & $3(2.7 \%)$ & $0.95(0.18-4.90)$ & \\
\hline & & & Dominant & $\mathrm{C} / \mathrm{C}$ & $52(66.7 \%)$ & $55(49.5 \%)$ & 1 & 0.019 \\
\hline & & & & $\mathrm{G} / \mathrm{C}-\mathrm{G} / \mathrm{G}$ & $26(33.3 \%)$ & $56(50.5 \%)$ & $2.04(1.12-3.71)$ & \\
\hline \multirow[t]{3}{*}{$A G P A T 1$} & chr6_32248546 & snp725 & Codominant & $\mathrm{A} / \mathrm{A}$ & $58(77.3 \%)$ & $78(70.3 \%)$ & 1 & 0.44 \\
\hline & & & & $\mathrm{G} / \mathrm{A}$ & $15(20 \%)$ & $31(27.9 \%)$ & $1.54(0.76-3.11)$ & \\
\hline & & & & $\mathrm{G} / \mathrm{G}$ & $2(2.7 \%)$ & $2(1.8 \%)$ & $0.74(0.10-5.44)$ & \\
\hline \multirow[t]{3}{*}{ NOTC4 } & chr6_32286548 & rs17604492 & Codominant & $\mathrm{C} / \mathrm{C}$ & $66(85.7 \%)$ & $93(83.8 \%)$ & 1 & 0.53 \\
\hline & & & & $\mathrm{T} / \mathrm{C}$ & $9(11.7 \%)$ & $17(15.3 \%)$ & $1.34(0.56-3.19)$ & \\
\hline & & & & $T / T$ & $2(2.6 \%)$ & $1(0.9 \%)$ & $0.35(0.03-4.00)$ & \\
\hline
\end{tabular}

a The corresponding odds ratio (OR) is counted by age and gender adjustment. $95 \% \mathrm{CI}=95 \%$ confidence interval. ${ }^{\mathrm{b}}$ The $\mathrm{P}$ value is counted by the web-based tool SNPstats.

Table 3. Results of 7 single nucleotide polymorphisms (SNPs) in PR-positive/-negative groups.

\begin{tabular}{|c|c|c|c|c|c|c|c|c|}
\hline Nearest gene & SNP_ID & ID & Model & Genotype & Positive $(\mathrm{N})$ & Negative $(\mathrm{N})$ & OR $(95 \% \mathrm{CI})^{\mathrm{a}}$ & $\mathrm{P}^{\mathrm{b}}$ \\
\hline \multirow[t]{2}{*}{$B A T 2$} & chr6_31697494 & snp3363 & - & $\mathrm{C} / \mathrm{C}$ & $91(96.8 \%)$ & $93(100 \%)$ & 1 & 0.048 \\
\hline & & & & $\mathrm{C} / \mathrm{T}$ & $3(3.2 \%)$ & $0(0 \%)$ & $0.00(0.00-\mathrm{NA})$ & \\
\hline \multirow[t]{3}{*}{ BAT5 } & chr6_31763660 & snp3425 & Codominant & $\mathrm{C} / \mathrm{C}$ & $79(84 \%)$ & $76(83.5 \%)$ & 1 & 0.82 \\
\hline & & & & $\mathrm{T} / \mathrm{C}$ & $13(13.8 \%)$ & $14(15.4 \%)$ & $1.12(0.49-2.54)$ & \\
\hline & & & & $T / T$ & $2(2.1 \%)$ & $1(1.1 \%)$ & $0.52(0.05-5.85)$ & \\
\hline \multirow[t]{3}{*}{ LY6G6F } & chr6_31783744 & rs 2242653 & Codominant & $\mathrm{G} / \mathrm{G}$ & $20(21.5 \%)$ & $20(21.5 \%)$ & $20(21.5 \%)$ & 0.45 \\
\hline & & & & $\mathrm{A} / \mathrm{G}$ & $20(21.5 \%)$ & $20(21.5 \%)$ & $20(21.5 \%)$ & \\
\hline & & & & $\mathrm{A} / \mathrm{A}$ & $20(21.5 \%)$ & $20(21.5 \%)$ & $20(21.5 \%)$ & \\
\hline \multirow[t]{3}{*}{ C6orf 48} & chr6_31911109 & rs17201248 & Codominant & $\mathrm{C} / \mathrm{C}$ & $68(71.6 \%)$ & $61(66.3 \%)$ & 1 & 0.2 \\
\hline & & & & $\mathrm{C} / \mathrm{T}$ & $23(24.2 \%)$ & $30(32.6 \%)$ & $1.45(0.76-2.77)$ & \\
\hline & & & & $\mathrm{T} / \mathrm{T}$ & $4(4.2 \%)$ & $1(1.1 \%)$ & $0.28(0.03-2.56)$ & \\
\hline \multirow[t]{3}{*}{ ZBTB12 } & chr6 31975605 & snp704 & Codominant & $\mathrm{C} / \mathrm{C}$ & $56(58.3 \%)$ & $51(54.8 \%)$ & 1 & 0.58 \\
\hline & & & & $\mathrm{G} / \mathrm{C}$ & $36(37.5 \%)$ & $40(43 \%)$ & $1.22(0.68-2.20)$ & \\
\hline & & & & $\mathrm{G} / \mathrm{G}$ & $4(4.2 \%)$ & $2(2.1 \%)$ & $0.55(0.10-3.13)$ & \\
\hline \multirow[t]{3}{*}{ AGPATI } & chr6_32248546 & snp725 & Codominant & $\mathrm{A} / \mathrm{A}$ & $72(77.4 \%)$ & $63(67.7 \%)$ & 1 & 0.34 \\
\hline & & & & $\mathrm{G} / \mathrm{A}$ & $20(21.5 \%)$ & $27(29 \%)$ & $1.39(0.70-2.75)$ & \\
\hline & & & & $\mathrm{G} / \mathrm{G}$ & $1(1.1 \%)$ & $3(3.2 \%)$ & $3.75(0.37-37.69)$ & \\
\hline \multirow[t]{5}{*}{ NOTCH4 } & chr6_32286548 & rs 17604492 & Codominant & $\mathrm{C} / \mathrm{C}$ & $80(84.2 \%)$ & $79(85 \%)$ & 1 & 0.19 \\
\hline & & & & $\mathrm{T} / \mathrm{C}$ & $12(12.6 \%)$ & $14(15.1 \%)$ & $1.09(0.47-2.55)$ & \\
\hline & & & & $\mathrm{T} / \mathrm{T}$ & $3(3.2 \%)$ & $0(0 \%)$ & $0.00(0.00-\mathrm{NA})$ & \\
\hline & & & Recessive & $\mathrm{C} / \mathrm{C}-\mathrm{T} / \mathrm{C}$ & $92(96.8 \%)$ & $93(100 \%)$ & & 0.069 \\
\hline & & & & $\mathrm{T} / \mathrm{T}$ & $3(3.2 \%)$ & $0(0 \%)$ & $0.00(0.00-\mathrm{NA})$ & \\
\hline
\end{tabular}

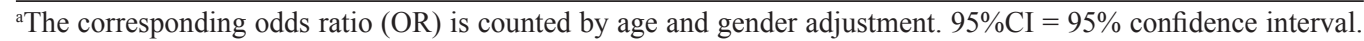
${ }^{\mathrm{b}}$ The $\mathrm{P}$ value is counted by the web-based tool SNPstats.

\section{DISCUSSION}

The MHC is located in the short arm of chromosome 6 , with gene-dense spanning $\sim 4$ $\mathrm{kb}$ and encoding over 160 genes. Approximately $40 \%$ of these genes encode proteins involved 
in the immune system, including the HLA membrane glycoprotein that mediates T-lymphocyte signaling. Many diseases, including autoimmune, neurological, reproductive, endocrinological, and malignant disorders, have been found associated with MHC (Gruen and Weissman, 2001). Polymorphisms of HLA are connected with many diseases, especially autoimmune disorders (Shiina et al., 2004). The human class III region, spanning approximately $700 \mathrm{~kb}$, contains 61 genes and is the most gene-dense region of the human genome (Xie et al., 2003). It is known for the complement component genes $C 4$ factor $\mathrm{B}(B F)$ and $C 2$, which encode subunit proteins for the $\mathrm{C} 3$ and $\mathrm{C} 5$ convertases, enzymes essential for the complement activation pathways of the humoral immune response (Yu, 1998; Milner and Campbell, 2001). This body of evidence indicates that genetic variants in the MHC class III region may be associated with malignant cancer.

Breast cancer is the most common malignancy among females worldwide. Several studies have investigated the association of the HLA class I and class II regions in breast cancer in different ethnic groups and areas (Ghaderi et al., 2001; Lavado et al., 2005; Baccar et al., 2006; Cantú de León et al., 2009; Gun et al., 2012; Mahmoodi et al., 2012). Attempts have also been made to reveal the relationship between the genes in the MHC class III region and mammary cancer. An earlier study carried out by Mestiri et al. (2001) found that genetic variation in $T N F-\alpha$ and $h s p$ 70-2, which are the genes in the class III region, could increase risk of breast carcinoma and may predict clinical outcome. The entire HLA class III region was then researched by de Jong et al. (2003), who suggested that HLA class III region may play a potential role in susceptibility to breast cancer in patients at moderate familial risk. In this study, we screened 9 SNPs in the MHC class III-coding region, which are in the genes reported to be of relevance to the occurrence of cancer, to investigate the association between breast cancer and MHC class III in the Chinese Han population. However, no significant association between HLA class III variants and breast cancer was detected in this population.

Breast cancer patients with tumors that are ER-and/or PR-negative experience higher risks of mortality after their diagnosis compared to women with ER- and/or PR-positive disease (Anderson et al., 2001; Dunnwald et al., 2007). An important implication of this is that variants determined in patients positive for these receptors could be related to good prognosis. In this study, we also stratified the analysis of the association between the 7 selected SNPs and ER- or PR-positive/-negative breast cancer. The results showed that chr6_31697494 in $B A T 2$ has a significant association with both ER- and PR-positive breast cancer. Furthermore, chr6_31911109 in C6orf48 and chr6_31975605 in ZBTB12 were found to be significantly correlated with ER-positive breast cancer.

The BAT2 gene (HLA-B-associated transcript) of unknown function is located in the HLA class III region, and polymorphic microsatellites have been identified between the $B A T 2$ gene and the TNF gene (Spies et al., 1989; Iris et al., 1993). This gene has microsatellite repeats, which are associated with the age-at-onset of insulin-dependent diabetes mellitus (IDDM) and thought to be involved with the inflammatory process of pancreatic $\beta$-cell destruction during the development of IDDM (Hashimoto et al., 1999). This gene is also a candidate gene for the development of rheumatoid arthritis (Singal et al., 2000). Similarly, C6orf48 (chromosome 6 open reading frame 48) and ZBTB12 (zinc finger and BTB domain containing 12) are expressed in various tumor tissues. Nevertheless, no studies have investigated the effect of the three genetic polymorphisms on susceptibility for breast cancer. Data presented here demonstrate that chr6_31697494, chr6_31911109 and chr6_31975605 are significantly correlated to ER- or PR-positive breast cancer. 
To sum up, the present study provides the first evidence that genetic polymorphisms in MHC class III region are insignificantly associated with breast cancer in our subjects. Further stratified analysis of the hormonal receptors showed a good prognosis in the chr6_31697494, chr6_31911109 and chr6_31975605 variations.

\section{ACKNOWLEDGMENTS}

Research supported by the Development Program for Technological Innovation and Platform Construction of Huai'an (Grant \#HAP201016), and the Development Program for Cooperative Innovation of Industry - University of Huai'an (Grant \#HAC0825).

\section{REFERENCES}

Anderson WF, Chu KC, Chatterjee N, Brawley O, et al. (2001). Tumor variants by hormone receptor expression in white patients with node-negative breast cancer from the surveillance, epidemiology, and end results database. J. Clin. Oncol. 19: 18-27.

Baccar HA, Yacoubi LB, Troudi W, Hmida S, et al. (2006). HLA class II polymorphism: protective or risk factors to breast cancer in Tunisia? Pathol. Oncol. Res. 12: 79-81.

Bhutia SK, Mallick SK and Maiti TK (2010). Tumour escape mechanisms and their therapeutic implications in combination tumour therapy. Cell Biol. Int. 34: 553-563.

Cantú de León D, Perez-Montiel D, Villavicencio V, Garcia CA, et al. (2009). High resolution human leukocyte antigen (HLA) class I and class II allele typing in Mexican mestizo women with sporadic breast cancer: case-control study. BMC Cancer 9: 48.

de Jong MM, Nolte IM, de Vries EG, Schaapveld M, et al. (2003). The HLA class III subregion is responsible for an increased breast cancer risk. Hum. Mol. Genet. 12: 2311-2319.

Dunn GP, Bruce AT, Ikeda H, Old LJ, et al. (2002). Cancer immunoediting: from immunosurveillance to tumor escape. Nat. Immunol. 3: 991-998.

Dunnwald LK, Rossing MA and Li CI (2007). Hormone receptor status, tumor characteristics, and prognosis: a prospective cohort of breast cancer patients. Breast Cancer Res. 9: R6.

Ghaderi A, Talei A, Gharesi-Fard B, Farjadian SH, et al. (2001). HLA-DBR 1 alleles and the susceptibility of Iranian patients with breast cancer. Pathol. Oncol. Res. 7: 39-41.

Gruen JR and Weissman SM (2001). Human MHC class III and IV genes and disease associations. Front Biosci. 6: D960-D972.

Gun FD, Ozturk OG, Polat A and Polat G (2012). HLA class-II allele frequencies in Turkish breast cancer patients. Med. Oncol. 29: 466-471.

Hashimoto M, Nakamura N, Obayashi H, Kimura F, et al. (1999). Genetic contribution of the BAT2 gene microsatellite polymorphism to the age-at-onset of insulin-dependent diabetes mellitus. Hum. Genet. 105: 197-199.

Iris FJ, Bougueleret L, Prieur S, Caterina D, et al. (1993). Dense Alu clustering and a potential new member of the NF kappa B family within a 90 kilobase HLA class III segment. Nat. Genet. 3: 137-145.

Jemal A, Bray F, Center MM, Ferlay J, et al. (2011). Global cancer statistics. CA Cancer J. Clin. 61: 69-90.

Lavado R, Benavides M, Villar E, Ales I, et al. (2005). The HLA-B7 allele confers susceptibility to breast cancer in Spanish women. Immunol. Lett. 101: 223-225.

Linos E, Spanos D, Rosner BA, Linos K, et al. (2008). Effects of reproductive and demographic changes on breast cancer incidence in China: a modeling analysis. J. Natl. Cancer Inst. 100: 1352-1360.

Mahmoodi M, Nahvi H, Mahmoudi M, Kasaian A, et al. (2012). HLA-DRB1, -DQA1 and -DQB1 allele and haplotype frequencies in female patients with early onset breast cancer. Pathol. Oncol. Res. 18: 49-55.

Mestiri S, Bouaouina N, Ahmed SB, Khedhaier A, et al. (2001). Genetic variation in the tumor necrosis factor-alpha promoter region and in the stress protein hsp70-2: susceptibility and prognostic implications in breast carcinoma. Cancer 91: 672-678.

Milner CM and Campbell RD (2001). Genetic organization of the human MHC class III region. Front Biosci. 6: D914-D926.

Shiina T, Inoko H and Kulski JK (2004). An update of the HLA genomic region, locus information and disease associations: 
2004. Tissue Antigens 64: 631-649.

Singal DP, Li J and Zhu Y (2000). HLA class III region and susceptibility to rheumatoid arthritis. Clin. Exp. Rheumatol. 18: 485-491.

Spies T, Blanck G, Bresnahan M, Sands J, et al. (1989). A new cluster of genes within the human major histocompatibility complex. Science 243: 214-217.

Xie T, Rowen L, Aguado B, Ahearn ME, et al. (2003). Analysis of the gene-dense major histocompatibility complex class III region and its comparison to mouse. Genome Res. 13: 2621-2636.

Yu CY (1998). Molecular genetics of the human MHC complement gene cluster. Exp. Clin. Immunogenet. 15: 213-230.

Ziegler RG, Anderson WF and Gail MH (2008). Increasing breast cancer incidence in China: the numbers add up. J. Natl. Cancer Inst. 100: 1339-1341. 